AC 2011-453: GENERAL AVIATION AIRPORT LAYOUT AND DESIGN:

A CROSS-DISCIPLINE EXERCISE IN DESIGN MANAGEMENT FOR FRESHMAN ENGINEERING STUDENTS.

Ibibia K. Dabipi, University of Maryland, Eastern Shore 


\section{GENERAL AVIATION AIRPORT LAYOUT AND DESIGN: A CROSS-DISCIPLINE EXERCISE IN DESIGN MANAGEMENT FOR FRESHMAN ENGINEERING STUDENTS.}

\section{Introduction}

Over the past four years, the aviation faculty at the University of Maryland Eastern Shore (UMES) have been working in conjunction with the engineering faculty within the department to develop a joint freshman engineering design experience aimed at a design course that is collaborative, multi-disciplined, hands on, aerospace industry focused, and helps students identify strengths and weaknesses they may have when working in team environments [1][2]. While focusing on aviation projects, the faculties from both the engineering and aviation programs seek to address the issues faced by students in both programs in a way that benefits the students. Practical projects provide the students with the understanding that their work is addressing a relevant industry need. Additionally, design projects such as this one introduces students to the type of group dynamics that they are likely to encounter at their future sites of employment where they will be expected to perform as a team. For this project, two teams were formed to address the same design problem. This paper examines the lessons learned during this collaboration and offers some insight into what challenges similar freshman engineering design courses may encounter.

\section{Design Course Project Review}

The Freshman Engineering Design Course at UMES has continued to operate in the same fashion since 2006. The engineering professor facilitates the course and introduces aspiring engineers to the knowledge, skills and abilities requisite for completing a design project. Jointly, Aviation Sciences faculties participate in the course by serving the role of both the client(s) and the users who provides the students with the aim, scope and constraints of the project. Both aviation faculty are Certified Flight Instructors with terminal graduate degrees in Aviation Sciences and serve as voluntary Federal Aviation Administration Safety Team (FAAST) Representatives. The aviation faculty, posing as clients, works with the course professor to guide team selection, answers student questions, and evaluate ongoing progress. The clients outline the expected deliverables and evaluate the final product at the end of the semester during the presentation portion of the course.

The theme of the course project subject has varied from semester to semester while staying within the confines of research areas in the aerospace/aviation field. Current areas of interest include small Unmanned Aerial Systems (sUAS) operations in the National Airspace System (NAS) for commercial remote sensing purposes and mitigation efforts related to latent conditions associated with safe operations. Due to restrictions on model aircraft usage for research purposes on campus (implemented by the Federal Aviation Administration in the United States), continued usage of powered model aircraft devices was not an option. In response, client centered projects focused on kite-based aerial platform designs [3] and other key aviation safety issues such as runway incursion avoidance [4]. 


\section{Course Design Evolution}

One of the issues confronting learning environments is the ability to integrate diversity of approach both in teaching and learning modalities. The course evaluation starts with an assessment of student leadership and cooperative skills which is extracted from an initial Team Formation Survey (TFS). Three approaches have been used to formulate teams for the project depending on the size of the class and the composition. In some semesters, the students after taking the TFS, form their own teams and select their leader while in other semesters, the leadership role is rotated weekly among the team members. A different approach is to divide the teams based on the survey results and assign the leadership role as well. In both team composition examples, each team executes the project from start to finish even when both groups have the same project constraints. Thus the assignments of individual student responsibilities are determined within the group structure. Critical to this dynamics is the management styles which evolve from the teams as they engage themselves within the project criteria, design and production phases of the project. Once the team formation is complete and the project assigned, the teams begin to meet and discuss the design process and the timeline for deliverables. Figures 1 and 2 exemplify the team meeting formats where individual team member ideas are critiqued and integrated into the final design.

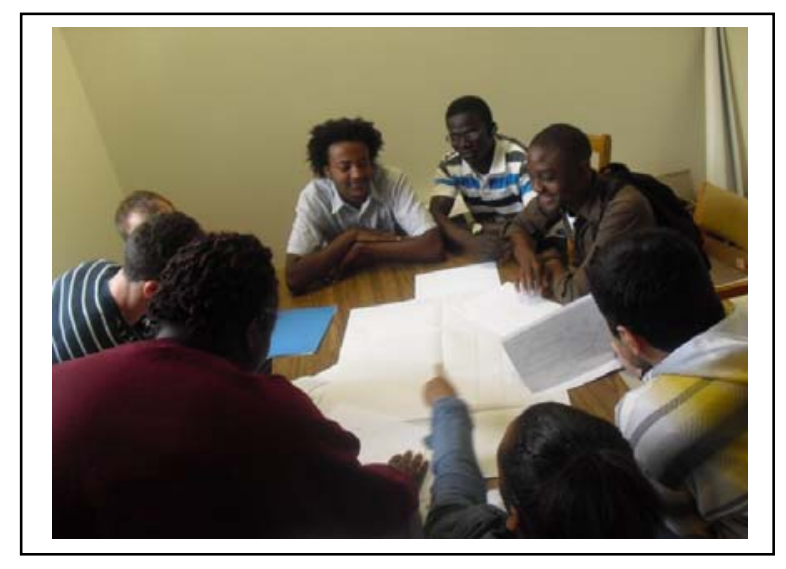

Figure1. Student's discuss design progress at a team conference

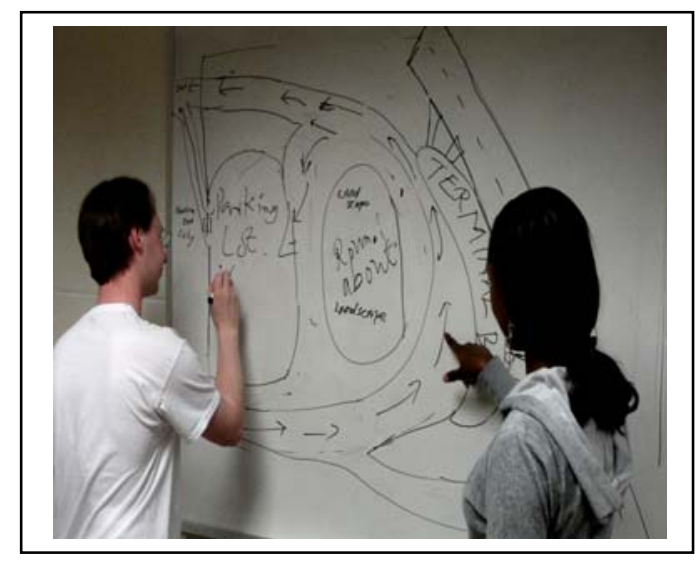

Figure 2. Students in second group critique design layout 


\section{Engaging Students Within The Engineering Design Principles}

Students in the spring 2010 engineering design course were given a written design problem statement and presentations by two of the Aviation Sciences faculty in their Department. Students were asked to design and build a simple regional airport that satisfies global usage. The basic requirements were; one terminal building, one runway, parking area, signage (no alpha/ numerical), and one main road in and out and everything must be visible from that entrance. The initial meeting included a question and answer period where student could ask key design questions to the faculty members playing the customer role. This session is initiated only when the class has fully researched the project by reviewing previous work done in the subject area. It is intended to provide students with a knowledge-base from which an intelligent discussion about the project can begin. The students' interaction with the client in the initial stage is also viewed as an opportunity for students to work on developing their communication skills. Throughout the course, students studied the design process through regular lectures with their course instructor which included key concepts such as team design, understanding the client's needs; functions and design specifications; generating design ideas; connecting design concepts to engineering objectives; outcome reporting; oral presentation skills and final report elements. A midterm examination is used to calibrate the level of understanding with the individual groups. It particularly addresses the communicating aspect of the course to examining the level of participation among the group members in identifying issues as well as how they were resolved. Following the midterm examination, a presentation of the status of the project with each group member participating in the presentation is undertaken. The challenges thus far are revealed at this stage and the input desired from both faulty and client augments the learning process.

\section{The Design Process}

As part of the evaluation process, the groups were required to demonstrate the evolution of their design process and document the decision-making process as they arrived at their final design. This process documents the progression as well as the team dynamics required to engage the team members assigned to each group. The team dynamics equally reveals the cultural and social diversity issues which these future engineers will face in a global economy and equally examines their resolution process. The design evolution figures 3, 4 and 5. The teamwork/social challenges encountered by the groups such as power struggles within the group, complaining, lack of motivation to complete the task, inability to keep everyone informed on the status of the project as well as sporadic or limited communication between group members informed our conclusions which will be discussed in the next section. 


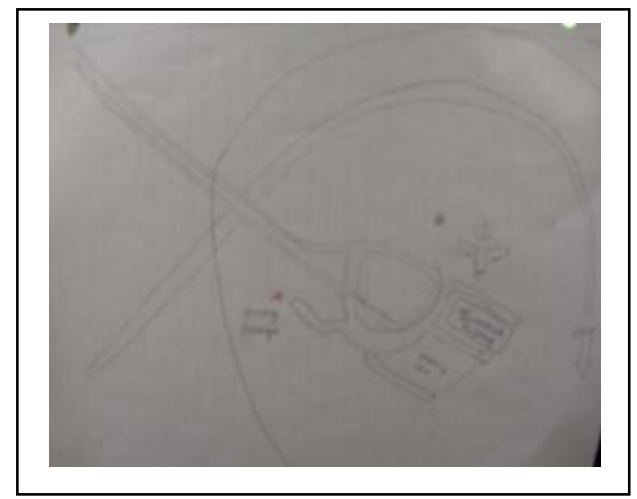

Figure 3. Initial Sketch of airport approach

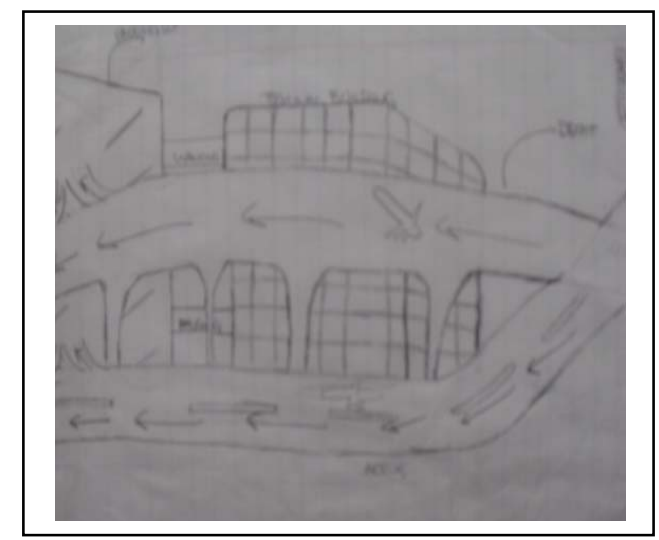

Figure 4. airport approach sketch with traffic flow information

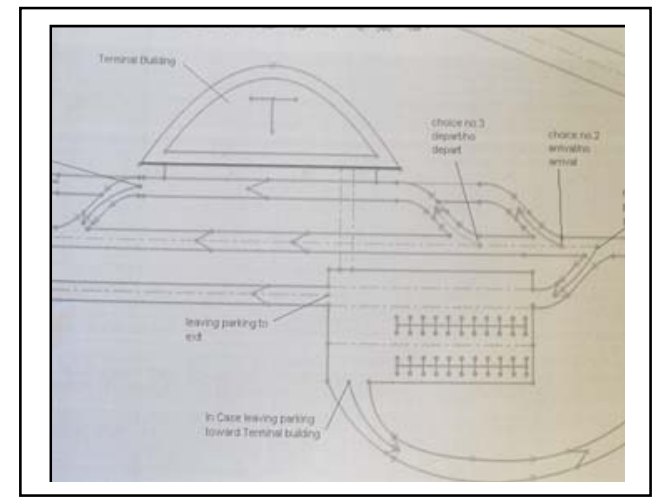

Figure 5. Final conceptual sketch

\section{Leadership Selection}

In general, our experience proved to highlight the negative consequences of student group/leader self-selection. That is, freshman students are generally poor judges of good team dynamics and often make poor leadership selection when asked to work on a team project. Since freshman engineering design occurs in the first semester, and students had not established sufficient relationships with each other through prolonged performance observation, they do not have the necessary information to select their own groups.

Faculty (engineering \& aviation sciences) quickly observed that students possessing the technical skill and leadership ability would step into the leadership role later in the semester, often 
unprompted, in an effort to correct previous leadership decisions. Groups having a unified understanding of cohort skill were more successful in their design progress. Groups that struggled were those lacking basic design skill history and those who had weak leadership. The lesson learned was that in the freshman level design projects, strong leaders are needed to prolong group cohesion and participation.

Early problems included the sense of not belonging in a design group. If group members perceived they were not a part of the group, they would often express their lack of confidence in group skill. Students participating in groups that felt included in project design reported being highly confident of their abilities even in cases where in-group and out-group ability levels were comparable.

Client and course facilitators realized that defenses against these types of failures might be erected by ensuring that groups all had equal amounts of diverse talent as well as assigned leaders that reported confidently the requisite skills necessary for project leadership and management.

Current procedures included an early assessment of the following information:

- Engineering history - family, friends, and/or personal

- Living arrangements - on campus/off campus

- Team-work related attributes self-report items

- Technical ability self-report items

This type of competency assessment is used to identify the traits of ideal performers [6] and help improve group performance levels. That is, groups are assembled based on this information in order to increase performance and address potential shortcomings. Each semester, faculty are able to evaluate the performance and suggest corrective action.

Additionally, faculty and clients currently ask students complete a leadership evaluation of their team leaders and compare those results to the team leader's self-evaluation. The result of these assessments will be shared with future student team leaders to help them identify potential problem areas that may affect overall team performance while completing the course assignment. A modified version of the Multiple Leadership Questionnaire (MLQ) found in Northouse's [5] leadership text is utilized in the class to complete this evaluation.

\section{Benefits}

These types of multidisciplinary activities help infuse technology into classroom and expose students to relevant real-world problems being addressed by contemporary researchers.

Students learned the value of planning ahead and the need to include determining site selection and availability for design construction and testing. Students discovered that they were able to meet the client's project request with limited time and resources by working together. In their final report, students emphasized the need for good communication between team members and 
the client. Clear documentation of tasks needed to be completed and finished is the key to staying on schedule and having team accountability.

Additionally, the ability to be open minded to differing approaches to solve the same problem is a good characteristic of members working in a team environment.

The aviation faculty at UMES benefit from the interaction with the Freshman Engineering Design course by finding alternative solutions to operational/training problems that arises as a result of integration of new technology into the National Airspace System (NAS). Students continue to develop diverse and thoughtful designs to address problems presented to them by the aviation faculty. Faculty continues to utilize the course to satisfy the need for multidisciplinary research on campus while identifying aspiring leaders for other aerospace related research opportunities on campus.

\section{Key Attributes}

Key attributes that have been identified by aviation and engineering faculty for successful completion of design projects have been identified through the collection of rich qualitative data. Sources of qualitative data in the Freshman Design course include: Presentation speeches and materials; individual and weekly logs and meetings with client(s); construction and other team work observation; final deliverable demonstration events; and class interaction. From these interactions, we have identified a few of the key attributes of successful students in the completion of the Freshman Engineering Design course. They include, but are not limited to:

- Involved- Regular reporting and querying of the client and faculty member. The emphasis here is timely communication with the client and faculty to address any perceived misconceptions on what the project entails.

- Experienced- Some previous design history. While all students do not enter the course with the same skill sets, it is necessary to establish the relative strengths of the students such that they can harness them collectively to achieve the desired objectives of the project.

- Social- Works well in a team environment. Is able to communicate his/her ideas effectively with others in his/her group. Understanding the fact that isolation or working on the entire project is not an option and to acquire the skills for integration and sharing of ideas even when the ideas are contentious

- Cultural Sensitivity - Considers that the group is made up of people of diverse backgrounds, ethics and values that must be considered an influencing part of the group dynamic. A lack of cultural sensitivity can create serious roadblocks to innovation and lead to a loss of group trust/respect.

- Follower- Great leaders learn to be great followers first. Followers know when to put the needs of the collective group before individual needs/desires to keep group unity and avoid conflict. Often, poor followers will deny the rest of the group the treasure of their abilities when their idea is not accepted by the rest of the group. 


\section{Acknowledgment}

We would like to acknowledge the Chesapeake Information Based Aeronautics Consortium for continuing to support our educational efforts in the area of aviation/aerospace research. Additionally, we are indebted to Mr. Geoff Bland and Mr. Ted Miles from NASA Wallops Flight Facility, Virginia who continues to support our activities related to remote sensing and aerospace education integration.

\section{References}

[1] Dabipi, I.K, Arumala, J.O., Burrows-McElwain, J.B., “Advancing Aviation Sciences Education Through Industry Partnerships”, 9th International Conference on Engineering Education, Session R-1A, 2006.

[2] Dabipi, I.K., Hartman, C.E., Burrows-McElwain, J.B., Mohseni, S., " Design and Construction of A Stereoscopic Aerial Imaging Platform: A Project-Based Platform for Teaching Freshman Engineering Students ", 38th ASEE/IEEE Frontiers in Education Conference, Session F4C, 2008.

[3] Dabipi, I.K., Hartman, C.E., Burrows-McElwain, J.B.,"A Kite-Based Aerial Imaging as a Freshman Engineering Design Project ", 39th ASEE/IEEE Frontiers in Education Conference, Session M1C-1, 2009.

[4] Dabipi, I.K., Burrows-McElwain, J.B., Hartman, C.E, "Low Cost Runway Incursion Detection System for General Aviation Airports", 40th ASEE/IEEE Frontiers in Education Conference, Session T1C-1, 2010.

[5] Northouse, P. Leadership: Theory and Practice. Sage Publications, London. Pp. 69-79, 151-159, 2007.

[6] Rothwell, W., Kazanas, H. Mastering the instructional design process: A systematic approach. Jossey-Bass, San Francisco. Pp. 67-68, 1998. 